the NIH conference, became an outspoken critic of the panel. He says that "chronic mastitis" is one of a list of major animal health effects of BST that also include "disseminated pathologic lesions" and adverse reproductive effects. These findings, he asserts, have been "covered up" by companies that are developing and testing BST and by officials at the Food and Drug Administration (FDA, Bethesda, MD) who have access to extensive data submitted by the companies. Although the NIH panel was made aware of these unpublished findings, he says, it excluded them from its deliberations, making the final report a "whitewash."

"I've seen nothing to make me believe there are catastrophic health effects on animals," states panelist Larry Smith, a professor in the department of dairy science, Ohio State University (Wooster). The panel "drew no conclusions" about the effect of BST on the disease, he says, because of "variation in mastitis in individual studies."

The panel did not review the large amount of data on many thousands of cows that have been submitted to officials of the FDA. "We did not ask for FDA data," says Grumbach. "FDA has a very big task in attempting to handle all this information. I am not aware of any collusion to withhold this information...[and] the committee did not find any evidence of scientific misconduct."

Epstein's charges are "groundless," claims Lee Miller, vice president of Monsanto's Animal Sciences Division (St. Louis, MO), a manufacturer of the hormone. "Our data show no significant additional problem with mastitis...related to BST." Company scientists are trying to "reduce the BST data, converting [them] to peerreviewed papers," Miller says.

Besides issuing conclusions about the health and safety of BST use, the panel recommended that several outstanding questions connected to its use deserve further study. Perhaps the most controversial finding is that levels of insulin-like growth factor-I (IGF-I), a peptide hormone, become elevated by two to five $\mathrm{ng} / \mathrm{ml}$ in milk from BST-treated cows over normal levels of three to $10 \mathrm{ng} / \mathrm{ml}$. "The importance of the increased amounts of IGF-I in milk from rBST-treated cows is uncertain," the panel report says. Conceivably the hormone could exert a local effect on tissues before it is digested and thus inactivated in the gastrointestinal tract. The panel thus recommends further study of IGF-I and other hormones and growth factors.

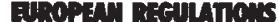

\section{UNIFIED APPROVALS, STANDARDS}

LONDON-One year away from staff of 100-150 (compared with 1992, harmonization in Europe continues. The final proposals for a $\mathrm{Eu}-$ ropean Medicines Agency, awaited since December 1989, have now emerged from the European Commission DGIII (Brussels). And in a separate initiative, comprehensive European standards for biotechnology processes, products, and equipment are being established.

The DGIII document, $\operatorname{COM}(90)$ 283 , sets 1993 as the deadline for establishing the European Medicines Agency, which will supercede the existing Committee for Proprietary Medicinal Products (CPMP) and its veterinary counterpart (CPVP). Mechanisms for both centralized and decentralized (mutually recognized) approvals are proposed-a compromise position reflecting the complexities of the transition towards harmonizing approvals. Biotechnology products would have to go through the centralized procedure.

European Federation of Pharmaceutical Industries Associations' (EFPIA) spokesman Peter O'Donnell generally welcomes the proposals: "Community-wide marketing authorization is absolutely vital....The Commission has done a reasonably good job." But he remains cautious about the remaining details. "We want to be sure that the five percent that's a bit iffy isn't going to be the five percent that throws everything out." EFPIA's concerns surround issues such as time frames and the makeup of specialist committees.

The most important difference between the new and the existing 87/22 procedures (Bio/Technology 8:894, Oct. ' 90 ) is that agency decisions would become binding. Under the centralized system, a rapporteur chosen by the agency-not the company involved, as under $87 / 22$ - would prepare an assessment report and present it to the CPMP (or CPVP, where appropriate), which would then give a binding scientific opinion as a draft decision. Objections by either the member state authorities or the company involved would trigger a mechanism for further consideration. The Commission would then adopt the Committee's scientific draft decision.

The head of the pharmaceuticals division of DGIII, which drafted the proposals, Fernand Sauer, said that he hoped the details would be completed this year. The agency would, he said, "not be a European FDA: it would be more a partnership with the 12 member states." With a permanent around 3,000 each for the U.S. Food and Drug Administration and the combined staffs of the European national authorities), its estimated annual budget would be 25-30 million ecu.

Several member states have offered to host the agency. Amsterdam and Copenhagen are the two front-running cities, having submitted detailed studies and cost breakdowns. Berlin, London, and Dublin have also shown interest, along with five French cities.

The site for the Medicines Agency is just one of several that European institutions will decide on at a series of intergovernmental "auctions" which began in Rome in mid-December. France, Belgium, and Luxembourg-already hosts of the European Parliament, Commission, and Court, respectively-are less likely to house the Medicines Agency.

Technical Committee 233 (TC 233) of the European Committee for Standardization (CEN, Brussels), responsible for standards in biotechnology, will publish its first report this month. TC 233 is an industry-oriented committee chaired by Brian Ager of SAGB (Brussels), with four working groups covering laboratory-scale practice, large-scale practice, agriculture/environment, and equipment.

As shown by a recent "green paper" from DGIII, the European Commission believes that setting standards is vital to the success of the single market. The large-scale document, for instance, would cover plant and product specifications as well as other relevant aspects-e.g. product quality, equipment performance, waste disposal, worker safety. That, says France Normand-Plessier of Sanofi (Paris), who chairs the large-scale working group, is just the sort of thing that administrators love to get their teeth into-which is why it is vital for those in industry to take the initiative, become proactive, and ensure that the standards become a "practical code."

January's TC 233 document will outline specific standards which need to be developed. Exactly what they should be will then be discussed with organizations in individual member states, which will serve as the conduit for the view of manufacturers nationally. It is likely that existing biotechnology standards, especially those already described by the French standards authority, AFNOR (Paris), will be used as a starting point.

-John Hodgson 